\title{
ANALISIS DAN PENGEMBANGAN JARINGAN HOTSPOT MENGGUNAKAN ROUTER MIKROTIK PADA PUSKESMAS BANDAR JAYA
}

\author{
Fitri Alvi Sukmawati G ${ }^{1)}$, Sudarmaji ${ }^{2)}$, Arif Hidayat ${ }^{3)}$ \\ ${ }^{\left.1-3^{*}\right)}$ Program Studi IImu Komputer, Fakultas IImu Komputer, \\ Universitas Muhammadiyah Metro
}

Jalan Gatot Subroto No. 100, Yosodadi, Metro Timur, Kota Metro

\begin{abstract}
Abstrak - Saat ini penggunaan hotspot banyak digunakan pada khalayak umum diantaranya adalah sekolah, perusahaan, instansi, universitas dan restaurant memanfaatkan hotspot baik digunakan untuk media bertukar informasi maupun pengolahan data. Dengan ini Jaringan Hotspot sangat diperlukan mengingat pada era sekarang sangatlah diperlukan sebuah jaringan. Penelitian ini bertujuan untuk: mengembangkan jaringan hotspot menggunakan router mikrotik agar lebih mudah dalam mengatur sebuah sistem jaringan yang berada pada Puskesmas Bandar Jaya, yang diharapkan dapat membantu dan mempermudah para staf yang berada pada di tempat penelitian. Tujuan penelitian yang dilakukan di Puskesmas Bandar Jaya adalah mengembangkan jaringan hotspot menggunakan metode NDLC. Metode yang digunakan dalam penelitian adalah Model Desain dan Implementasi Network Development Life Cycle (NDLC) yang dapat memberikan gambaran siklus yang awal dan akhirnya dalam membangun sebuah jaringan komputer yang mencakup sejumlah tahapan. Pengembangan jaringan hotspot termuat dalam laporan skripsi yang berjudul "Analisis dan Pengembangan Jaringan Hotspot Menggunakan Router Mikrotik Pada Puskesmas Bandar Jaya"
\end{abstract}

Kata Kunci: Analisis, Pengembangan, Puskesmas, Network Development Life Cycle (NDLC).

Abstract - Currently, the use of hotspots is widely used in the general public including schools, companies, agencies, universities and restaurants utilizing hotspots both for media exchanging information and data processing. With this, the Hotspot Network is very much needed considering that in the current era, a network is needed. This study aims to: develop a hotspot network using a mikrotik router to make it easier to manage a network system located at the Bandar Jaya Health Center, which is expected to help and facilitate the staff at the research site. The purpose of the research conducted at the Bandar Jaya Health Center is to develop a hotspot network using the NDLC method. The method used in this research is the Network Development Life Cycle (NDLC) Design and Implementation Model which can provide an overview of the initial and final cycle in building a computer network that includes a number of stages. Hotspot network development is contained in the thesis report entitled "Analysis and Development of Hotspot Networks Using Mikrotik Routers at Bandar Jaya Health Center"

Keywords : Analysis, Development, Puskesmas, Network Development Life Cycle (NDLC) 


\section{PENDAHULUAN}

Hotspot merupakan salah satu bentuk pemanfaatan teknologi wireless LAN pada lokasi public. Konsep ini pertama kali dimunculkan pada tahun 1993 oleh Bret Stewart pada saat konferensi Networld dan Interop, di San Fransisco. Saat ini penggunaan hotspot banyak digunakan pada khalayak umum diantaranya adalah sekolah, perusahaan, instansi, universitas dan restaurant memanfaatkan hotspot baik digunakan untuk media bertukar informasi maupun pengolahan data. Dengan ini Jaringan Hotspot sangat diperlukan mengingat pada era sekarang sangatlah diperlukan sebuah jaringan.

LAN ini memungkinkan adanya hubungan antara para pengguna informasi walaupun pada saat ini kondisi mobile (bergerak), sehingga memberikan kemudahan kepada pengguna informasi dalam melakukan aktivitasnya.Salah satu manfaat dari jaringan komputer yaitu sebagai media komunikasi antar pengguna dalam suatu jaringan komputer. Sistem komunikasi merupakan bentuk nyata dari komunikasi yang sudah banyak dirasakan manfaatnya sebagai media komunikasi oleh pengguna jaringan komputer

Penggunaan jaringan komputer yang di bangun pada salah satu ruang publik yaitu Puskesmas Bandar Jaya, Lampung Tengah sudah tersedia. Selanjutnya untuk meningkatkan pelayanan terhadap kesehatan masyarakat, saat ini dibutuhkan pengoptimalisasi jaringan, agar proses pelayanan terhadap pasien berjalan lancar untuk penginputan data dan lain sebagainya dibutuhkan jaringan yang sangat mendukung, karena pelayanan pada puskesmas bandar jaya sudah menggunakan sistem informasi berbasis website. Dan artinya itu pelayanan data pada puskesmas bandar jaya sudah menggunakan jaringan internet.

Jaringan komputer yang di bangun pada Puskesmas Bandar Jaya yaitu menggunakan kabel LAN (Local Area Network). Jaringan tersebut digunakan kurang lebih 25 pengguna (user) dengan 4 hub, pada ruangan yang berbeda di puskesmas bandar jaya, dan jumlah kecepatan yang tersedia 50 Mbps. Kecepatan ini dibagi ke seluruh bagian pada puskesmas bandar jaya menggunakan kabel jaringan LAN. Pada puskesmas Bandar Jaya memiliki hanya 1 Access Point yang terletak pada lantai yang berbeda dan 1 unit Modem, yang artinya , 1 unit modem tersebut dibagi dan di hubungkan ke semua ruangan yang ada di tempat tersebut. Sehingga di masing - masing ruangan memiliki jalur jaringan internet menggunakan media kabel LAN yang berbeda di ruangan tersebut. Pada waktu tertentu yaitu jam padat koneksi jaringan di Puskesmas Bandar Jaya menjadi lambat, dikarenakan penggunaan acces yang bersamaaan oleh para staf untuk memberikan pelayanan pada pasien yang akan mendaftar berobat maupun meminta rujukan ke rumah sakit lain yang berbasis web. Dan secara tidak langsung 1 modem yang berkapasitas 50 Mbps memungkinkan digunakan seluruh pengguna untuk mengolah data menggunakan internet lebih cepat apabila hanya 1 User yang menggunakannya, namun apabila seluruh staff menggunakan dengan waktu yang bersamaan maka koneksi pun akan melambat

Berdasarkan latar belakang diatas penulis dapat merumuskan permasalahan mengenai sistem informasi kepegawaian yakni:

a. Bagaimana management jaringan pada Puskesmas Bandar jaya di Lampung Tengah? 
b. Bagaimana penggunaan mengoptimalkan bandwidth menggunakan router Mikrotik agar tidak lambat pada Puskesmas Bandar Jaya?

Tujuan yang ingin dicapai oleh penulis melalui penelitian ini adalah sebagai berikut:

a. Untuk mengimplementasikan jaringan menggunakan Router Mikrotik pada Puskesmas Bandar Jaya Lampung Tengah

b. Untuk mengoptimalkan penggunaan bandwidth jaringan hotspot menggunakan Router Mikrotik agar tidak lambat pada Puskesmas Bandar Jaya .

\section{KAJIAN PUSTAKA DAN LANDASAN TEORI}

Analisis

Menurut Spradley yang dikutip dari Sugiyono, (2015:335), menyimpulkan bahwa Analisis atau analysis (analisa) adalah: "sebuah kegiatan untuk mencari suatu pola selain itu analisis merupakan cara berpikir yang berkaitan dengan pengujian secara sistematis terhadap sesuatu untuk menentukan bagian, hubungan antar bagian dan hubungannya dengan keseluruhan. Jadi dapat ditarik kesimpulan bahwa analisis merupakan penguraian suatu secara sistematis dalam menentukan bagian, hubungan antara bagian serta hubungannya secara menyeluruh untuk memperoleh pengertian dan pemahaman yang tepat".

\section{Wi-Fi}

Menurut Priyambodo

(2005:1)

menyimpulkan bahwa : "Wi-Fi merupakan singkatan dari Wireless Fidelity yaitu sebuah media penghantar komunikasi data tanpa kabel yang bisa digunakan untuk komunikasi atau mentransfer program dan data dengan kemampuan yang sangat cepat.Teknologi Wi-Fi yang diimplementasikan biasanya adalah standar IEEE 802.11g karena standart tersebut lebih cepat untuk proses data dengan jangkauan jaringan yang lebih jauh serta dukungan vendor. Pada umumnya, untuk bisa terhubung dengan sebuah perangkat elektronik, Wifi menggunakan frekuensi gelombang radio dalam rentang 2,4GHz s/d $5 \mathrm{GHz}$. pada tahun 1997 muncul jaringan wireless yang diberi nama 802.11 oleh IEEE (Institute of Electrical and Electronic Engineers). tahun 1999 muncul wireless B yang memiliki kecepatan transfer data 11 Mbps. tahun 2003 muncul Wireless G dengan kecepatan data transfer hingga 54 Mbps. tahun 2009 Wireless N dengan kecepatan transfer data 300 Mbps dan tahun 2014 muncul Wireless AC yang mempunyai kecepatan transfer data hingga $1 \mathrm{~GB}$ dan beroperasi pada frekuensi $5 \mathrm{GHz}$ ".

\section{Jaringan Komputer}

Novrianda (2017:29) menyimpulkan "jaringan komputer (Computer Network) adalah suatu himpunan interkoneksi sejumlah komputer autonomous".

\section{Sistem Operasi}

Menurut Herlina Latipa S., dkk(2013:3) yang dikutip dari Ari (2010:1), menyimpulkan bahwa: "Secara sederhana sistem operasi dapat didefinisikan sebagai antarmuka antara user dengan hardware. Atau dengan kata lain sistem operasi merupakan software yang digunakan untuk mengatur kerja hardware serta menyediakan lingkungan dimana seorang user dapat menjalankan program aplikasi. Berikut ini adalah sistem operasi yang sering digunakan oleh pengguna komputer, antara lain Windows $(95,98$, 
ME, 2000, XP, Windows 7, Windows8, Windows 10).,Linux, (Ubuntu, Mint, Debian, Redhat, Slackware, OpenSuse), Macintosh (khusus untuk macintosh hanya dapat digunakan secara resmi pada perangkat dari produk Apple)"

\section{Mikrotik}

Menurut Ontoseno, dkk., (2017:127) menyimpulkan sebagai berikut: "Mikrotik adalah sistem operasi komputer dan perangkat lunak komputer yang digunakan untuk menjadikan komputer biasa menjadi router, mikrotik dibedakan menjadi dua yaitu Mikrotik RouterOS dan Mikrotik Routerboard, untuk Mikrotik Routerboard tidak memerlukan komputer dalam menjalankannya cukup menggunakan board yang sudah include dengan Mikrotik RouterOS"

\section{VM Virtualbox}

Menurut Sidiq Syamsul Hidayat dan kawan kawan (2013:1) adalah: "Oracle VM Virtualbox adalah software virtualisasi open source yang memungkinkan penggunanya untuk menjalankan satu atau lebih sistem operasi dalam satu mesin virtual saat menjalankan windows. Program di design dengan mudah menggunakan antarmuka dan langkah demi langkah yang sangat memukau memungkinkan anda untuk membuat vm pertama anda dalam hitungan menit. Virtualbox sepenuhnya mendukung shared folder untuk pertukaran data yang mudah antara host dan tamu, serta remote desktop protocol (RDP), USB Virtual Controller dan USB melalui RDP".

\section{Winbox}

MADCOMS (2016: 63) menarik kesimpulan sebagai berikut: Winbox adalah sebuah utility yang digunakan untuk melakukan remote ke server MikroTik anda dalam mode GUI". Jika untuk mengkonfigurasi MikroTik dalam text mode melalui PC itu sendiri, maka untuk mode GUI yang menggunakan Winbox ini, anda dapat mengkonfigurasi MikroTik melalui komputer client.

\section{METODE}

Menurut James E. Goldman (20002:205), Development Life Cycle (NDLC) menyatakan bahwa NDLC merupakan suatu pendekatan proses dalam komunikasi data yang menggambarkan siklus yang awal dan akhirnya dalam membangun sebuah jaringan komputer yang mencakup sejumlah tahapan, yaitu: Analisis, Desain, Simulasi , Implementasi dan monitoring

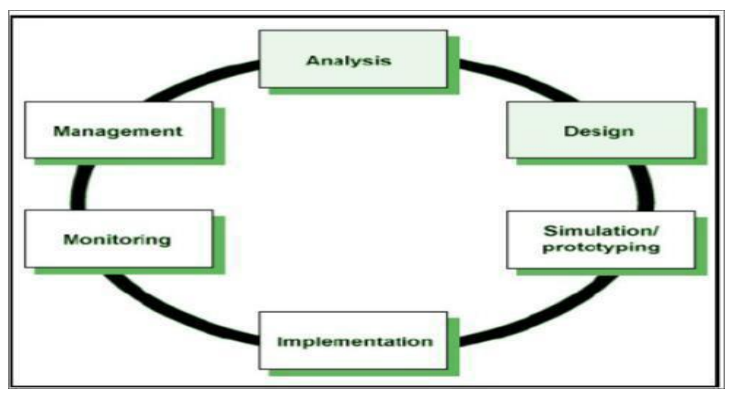

Gambar 1. Metode NDLC.(Sumber. James E. Goldman (20002:205)

\section{HASIL DAN PEMBAHASAN}

Topologi Jaringan

Langkah awal dalam melakukan perancangan sistem jaringan untuk Puskesmas Bandar Jaya diperlukan gambaran topologi jaringan, topologi yang akan digunakan adalah topologi star, gambaran topologi yang hendak digunakan sebagai yaitu berikut: 


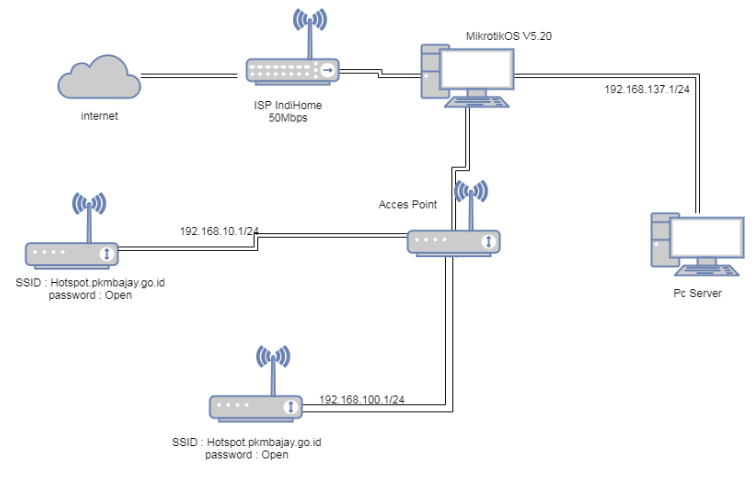

Gambar 2. Rancangan Topologi Jaringan

\section{Setting Bridge Pada \\ VirtualBox}

Melakukan setting bridge pada VirtualBox diperlukan karena untuk menentukan berapa port yang hendak digunakan dan juga menentukan peran dari setiap port nya.

\section{Install MikroTik}

Berikut merupakan instalasi machine MikroTik OS di VirtualBox yang akan digunakan sebagai router jaringan untuk memanajemen bandwidth dan firewall filtering sistem jaringan di Puskesmas Bandar Jaya.

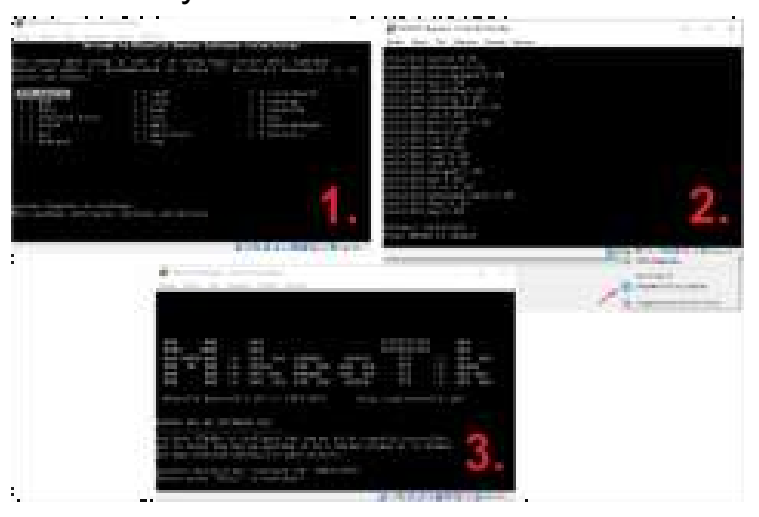

Gambar 3. Instalasi MikroTik OS.

\section{Konfigurasi Hotspot}

Berikut merupakan konfigurasi hotspot setting menggunakan MikroTik router. Output dari hotspot setting berupa jaringan wireless agar perangkat HP atau laptop user dapat terkoneksi, langkah-langkah setting hotspot dapat

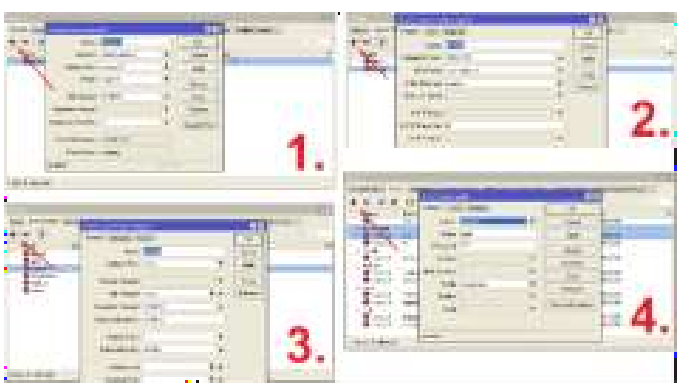

dilihat pada Gambar 5.

Gambar 4. Konfigurasi Hotspot.

\section{User Manajemen Bandwidth}

Manajemen bandwidth berfungsi untuk mengatur bandwidth dari setiap user yang ada malai dari user jaringan lokal atau LAN dan jaringan hotspot agar penggunaan jaringan menjadi lebih baik, cepat, efektif dan efisien.
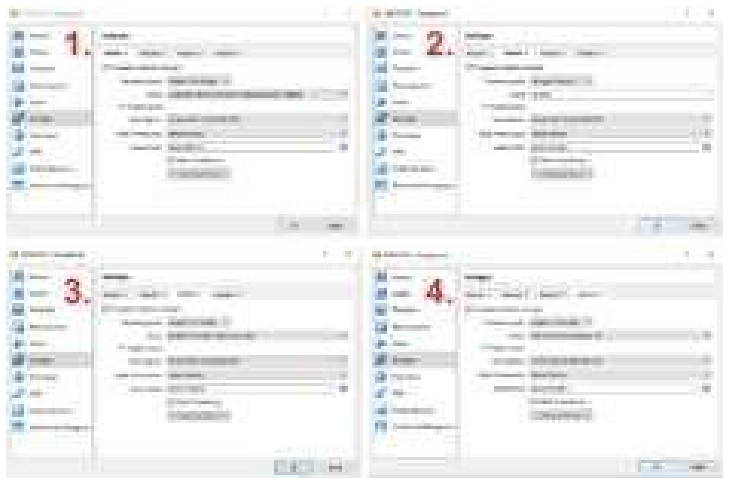

Gambar 5. User manajemen bandwidth.

\section{Testing Jaringan}

Dari konfigurasi yang telah dilakukan berikut merupakan testing jaringan yang terdiri dari jaringan LAN, hotspot, manajemen bandwidth, dan firewall filtering, hasil dari testing jaringan dapat dilihat pada Gambar 6.

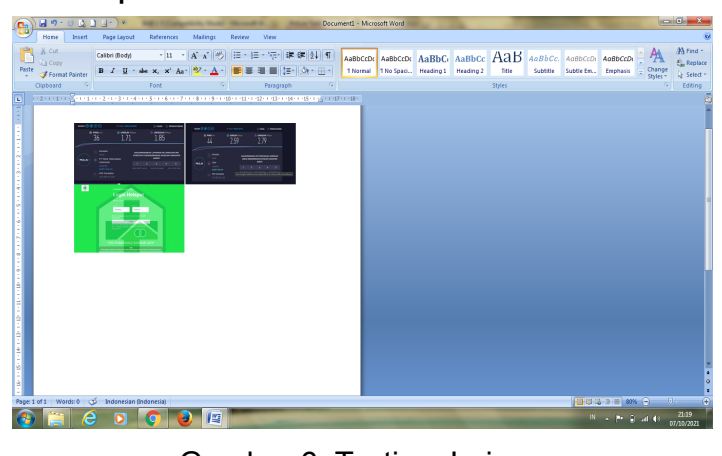

Gambar 6. Testing Jaringan 


\section{Kesimpulan}

Setelah melakukan kegiatan penelitian pada Puskesmas Bandar Jaya, maka penulis dapat menyimpulkan bahwa kondisi sistem jaringan yang sudah berjalan sudah cukup baik, namun ada beberapa kekurangan yaitu :

Belum adanya manajemen bandwidth secara menyeluruh pada jaringan internet, karena hal ini mengakibatkan aktivitas menjadi lambat dikarenakan kebebasan untuk mengakses internet

Ruang Lingkup akses jaringan internet yang bebas di PKM Bandar Jaya sehingga jaringan internet dapat diakses semua orang yang bukan staff dari PKM Bandar Jaya. Oleh karena itu, penulis membangun sistem jaringan guna untuk memanajemen aktivitas jaringan sehingga sistem yang sedang berjalan dapat lebih optimal. Adapun beberapa kesimpulan, yaitu :

a. Pada sistem yang dibangun juga terdapat fitur untuk membatasi

\section{DAFTAR PUSTAKA}

[1] Sugiyono (2015). Metode Penelitian Kombinasi (Mix Methods). Bandung: Alfabeta.

[2] Priyambodo, TK. 2005. Jaringan Wi-Fi Teori dan Implementasi. Jakarta: Andi

[3] Novrianda, R. (2017). Rancang bangun keamanan jaringan wireless pada STIPER

[4] Sriwigama Palembang dengan radius server. Jurnal Maklumatika, 4(1), 19-29.

[5] Ontoseno, R Dio Handoyo.2017. Limitasi Penggunaan Akses Internet atau memanajemen bandwidth yang digunakan user sehingga jaringan dapat diawasi, dikontrol dan diatur sesuai kebutuhan.

b. Memperluas ruang lingkup akses jaringan internet PKM Bandar Jaya hanya di area instansi, untuk mengurangi orang luar menggunakan akses karena sudah adanya penerapan login dan para staf dapat mengakses jaringan internet dengan mudah di lingkungan PKM Bandar Jaya saja.

c. Dengan adanya pembagian bandwidth yang dibuat dapat memberikan kemudahan dan memenuhi kebutuhan pengguna di PKM Bandar Jaya dalam mengakses internet melalui jaringan dengan harapan memudahkan pekerjaan para staf.

Berdasarkan Kuota Waktu Dan Data Menggunakan PC Router OS Mikrotik( Studi Kasus: SKM YPM 7 Tarik).

[6] MADCOMS. 2016. Manajemen Sistem Jaringan Komputer Dengan Mikrotik RouterOS. Edisi Pertama. Andi. Yogyakarta.

[7] Goldman, James E. dan Rawles, P. T. (2001). Applied Data Communications A Business Oriented Approach, 3th Edition. John Wiley \& Sons, Inc. 